\title{
MyWallMate: An Investigation into the use of Mobile Technology in Enhancing Student Engagement
}

\author{
Chelsea Dobbins $^{1}$ (D) Philip Denton ${ }^{2}$
}

Published online: 19 April 2017

(C) The Author(s) 2017. This article is an open access publication

\begin{abstract}
This paper is a report of an investigation in which mobile technologies were used during large lecture-type sessions in tandem with the Textwall ${ }^{\mathrm{TM}}$ software. This online program is able to receive and present messages from students' devices that the lecturer may then share. It also can be used to collect student votes on multiple-choice questions, facilitating dynamic formative assessments during class. A study has been undertaken around the MyWallMate mobile application. This program has been developed by Liverpool John Moores University to expedite the process of sending messages and votes to Textwall ${ }^{\mathrm{TM}}$. Results of this study indicated that students had a positive reaction to both Textwall ${ }^{\mathrm{TM}}$ and the MyWallMate application. They reported being more comfortable in expressing their opinions via the MyWallMate mobile application and felt that using mobile technology within their lectures enhanced their learning. It has been concluded that the use of mobile technologies and BYOD-type approaches are avenues worth further exploration in global higher education.
\end{abstract}

Keywords Student engagement $\cdot$ Mobile applications $\cdot$ Bring your own device $\cdot$ Formative assessment

Chelsea Dobbins

C.M.Dobbins@ljmu.ac.uk

Philip Denton

P.Denton@ljmu.ac.uk

1 Department of Computer Science, Liverpool John Moores University, Byrom Street, Liverpool L3 3AF, UK

2 School of Pharmacy and Biomolecular Sciences, Liverpool John Moores University, Byrom Street, Liverpool L3 3AF, UK

\section{Introduction}

Student engagement and interaction is a multidimensional concept that has been at the forefront of higher education institutions around the globe over the last 10 years (Krause 2005). It is an area that is concerned with the relation between the time and effort that has been invested by both students and their institutions in optimising their experience and enhancing their learning (Trowler 2010). Furthermore, it is an important subject that is associated with, "positive academic outcomes, including achievement and persistence" (Fredricks et al. 2004, p. 87).

Improving student experience and enhancing learning in a manner that develops critical thinking, fosters student interaction and empowers students to learn through questioning is an important pedagogic topic, which has stimulated debate throughout higher education, including at institutions within the UK (Trowler 2010), USA (Kuh et al. 2008) and Australia (Coates 2005). This interest has led to a growing examination of this area in order to better understand how students interact with their course and how this interaction can be improved (Krause and Armitage 2014; Kuh 2003). The concept of student interaction and engagement is quite complex and covers a range of areas, from in-class attendance to involvement in curriculum design and informing institutional academic policies. When trying to deconstruct students' experiences of teaching, engagement may be divided into three categories; behavioural, emotional, and cognitive (Fredricks et al. 2004; Trowler 2010), Fig. 1.

As illustrated in Fig. 1, student engagement is a multifaceted area that is composed of many aspects that work in synergy. The work in this paper focuses on the behavioural aspects of student engagement. Whilst all aspects are important, the influence of behavioural factors on student engagement is evidenced in part by strong correlations between attendance 
Fig. 1 Aspects of Student Engagement within taught contexts



and attainment (Burd and Hodgson 2006; Colby 2005; Field 2012; Krause and Armitage 2014; van Schalkwyk et al. 2010). In spite of this, attendance remains an issue within higher education and has been the subject of numerous investigations, including from the UK (Burd and Hodgson 2006; Field 2012), Europe (Landin and Pérez 2015), USA (Friedman et al. 2014), South Africa (van Schalkwyk et al. 2010) and Australia (Dolnicar et al. 2009).

Previous studies have emphasised the importance of interactivity on student engagement and its positive impact on student's learning (Astin 1984; Hake 1998; Prince 2004; Trowler 2010). For instance, Steinert and Snell (1999) comment that interactive sessions are more stimulating and that these approaches increased the probability that students would attend in the future. Additionally, Hake (1998) found that courses that utilised interactive engagement (IE) showed a significant improved performance compared to those that used very little or no use of IE. Whilst Astin (1984, p. 528-529) concludes, "The greater the student's involvement in college, the greater will be the amount of student learning and personal development". As such, this research capitalises on trends within the adoption of mobile technology to explore innovative ways of promoting IE. Mobile devices (e.g. smartphones, tablets, etc.) have become ubiquitous and play such an essential role in the everyday living of modern students (Dahlstrom and Bichsel 2014; Rothwell 2016). This technology presents a unique method to engage with students on a level that they are familiar with using.
As interaction and engagement is such an important topic, the motivation of this research is set in the context of capitalising on the ubiquity of mobile devices and their use within higher education. As such, the overall purpose of this research is to examine how mobile devices can be used to engage with the modern student and poses the questions do mobile devices increase student engagement within lectures? Do students enjoy using their devices within lectures? We envision that incorporating such technology into the classroom will enhance the student experience, especially in large lectures where it is often more difficult to interact.

\section{Rationale for the Study: Mobile Technology and Student Engagement}

Over the past decade, enhancements in connectivity have led to mobile technologies (e.g. smartphones, tablets, etc.) becoming deeply woven into the everyday lives of students. For instance, in a recent study undertaken by Dahlstrom and Bichsel (2014), it was established that $99 \%$ of undergraduate students own a mobile Internet-enabled device, including $86 \%$ who own a smartphone and $47 \%$ who own a tablet. Interacting with these devices usually involves the use of mobile applications. In another study by Bowen and Pistilli (2012), it was reported that students spend more time (up to $3.6 \mathrm{~h}$ per day) using mobile apps, compared with mobile web browsers, which accounted for up to $1.8 \mathrm{~h}$. This rise in mobile device 
ownership presents teaching staff in higher education with a unique opportunity to explore the potential and positive use of such devices for educational use. This is supported by Bowen and Pistilli (2012), who have established that $83 \%$ of students use their smartphones for educational purposes, of which $49 \%$ preferred to use educational-related mobile apps. This rise in smartphone usage has stimulated interest in understanding the pedagogical implications of using technology as a means to engage students (Trowler 2010). Understanding students' preferences and embracing technology can allow pedagogical practises to develop in new and innovative ways. This can translate into positive uses within education as this understanding can also influence the creation of new mobile services that can help students be more successful (Bowen and Pistilli 2012). Additionally, as observed by Pegrum (2015), as device ownership increases, many educational institutions are moving towards bring your own device (BYOD) approaches, which minimises hardware costs for institutions. These technologies offer an excellent opportunity for enhancing learning and, instead of shunning mobile devices, it is important that educators embrace using this type of technology and capitalise on their popularity (Ally and Prieto-Blázquez 2014).

One area that has flourished as a result of technological developments is mobile learning (m-learning). Whilst there is no definitive definition of m-learning, it can be defined as "learning that takes place via such wireless devices as mobile phones, personal digital assistants (PDAs), or laptop computers" (O'Malley et al. 2005, p. 6). It can also be thought of as the juncture between mobile computing and e-learning, whereby learning is facilitated through the use of information and communication technology (ICT) and mobile devices (Jacob and Issac 2008). More recently, Pegrum (2015, p. 143 ) has defined it as, "learning supported by mobile devices. It is primarily the principle of mobility that differentiates $m$ learning from e-learning and other kinds of learning, which normally take place in fixed locations." Nevertheless, throughout the different definitions encountered in the literature, it is only the employment of specific types of technology that seem to differentiate mobile learning from other forms of learning (O'Malley et al. 2005). This type of learning provides a flexible solution as smartphones now offer virtually widespread 4G/3G/Wi-Fi wireless connectivity to the internet, which allows resources, such as course content, to be accessible from anywhere where the user has an internet connection (Crow et al. 2010; Woodcock et al. 2012). Additionally, this approach offers an innovative solution to interact with students during taught sessions in traditional classroom settings. Many initiatives have been undertaken by higher education institutions to promote the use of m-learning (Bachmann et al. 2015; Crow et al. 2010; Lopez et al. 2015; Ntinda et al. 2014). For example, mobile devices have been used as collaborative tools to increase motivation around exam preparation (Lopez et al. 2015). Within this study, a mobile application was developed that connected users with a database of exam questions and this enabled students to send in their own questions. The University of Namibia have also used an m-learning system (m-LSEMC) within their mathematics department. It has been reported that $93 \%$ of students who used the system to revise their subject gained improved results (Ntinda et al. 2014). Work by Page (2014) aimed to explore the rise of mobile applications and their effect on product design teaching. The results found that the most common use of applications was for sharing and presenting work, as opposed to creating it. Students felt that applications, such as Dropbox ${ }^{\mathrm{TM}}$, were useful for such tasks. The role of mobile applications within medical education has also been investigated. Lewis et al. (2014) found that mobile anatomy applications that can generate 3D models helped students to visualise and manipulate complex anatomical structures and that the addition of other digital content, including clinical correlations, instructional videos, and interactive quizzes, was beneficial.

Several investigations have been undertaken that have examined the perceptions that students have towards m-learning. A study by Woodcock et al. (2012) highlighted that many students were largely unaware of the potential for mobile devices to support learning, but that the majority were interested and receptive to the idea of integrating their devices within lectures. Similarly, Gikas and Grant's (2013) study around student perceptions of m-learning found that the apparent benefits were outweighed by the perceived drawbacks. Advantages included; rapid access to information; enhanced communications with fellow classmates and the lecturer; the use of online polls, video, voice memos and social media in teaching; and the delivery of course content within a real-world setting. Disadvantages included the perceived unwillingness of some staff to incorporate technology within their sessions. There were also occasional issues with the devices themselves, such as the size of the keyboard and applications not working as fluidly as expected.

University institutions in Brazil have investigated the usability of mobile devices in higher education (Bachmann et al. 2015). They found that while students were familiar with these gadgets, some teachers were not and would struggle to adapt to these evolving technologies. They uncovered a number of barriers that needed to be overcome, including the dispersion of students, teacher training, and the cost of the devices and connectivity (Bachmann et al. 2015). Work by Cheon et al. (2012), based on the theory of planned behaviour (TPB), indicates that those who felt that m-learning was easy to use and useful were more likely to use the technology within their learning.

\section{The MyWallMate Mobile Application Study}

Based on the research and the prevalence of mobile devices in modern society, our hypothesis is that the introduction of 
mobile technology into lectures is a suitable method for engaging students and will allow them to become more involved in the lectures. In order to address this hypothesis, a study has been undertaken around the MyWallMate mobile application. This application has been used during large lecture-type sessions in tandem with the Textwall ${ }^{\mathrm{TM}}$ web-based tool. Using the short message services (SMS), a dedicated web form, or email, this online program is able to receive and present messages from students' mobile devices that the lecturer may then share. It can also be used to collect student votes on multiplechoice questions, facilitating dynamic formative assessments during class. However, a drawback of the tool is that users must append a code that is unique to each tutor at the commencement of all messages and votes that are sent to the system. Anecdotal evidence suggests that errors around entering the code are not uncommon and that this discourages students from using the system in class (Mackley 2014). In addition, sending messages via short message services (SMS) may incur a charge for the student (Tarrant 2012). In response to these drawbacks, the MyWallMate ${ }^{1,2}$ mobile phone application was developed and a survey of student responses to both Textwall ${ }^{\mathrm{TM}}$ and the mobile application has been undertaken. This application is cross-platform (Android/iOS) and has been developed to make the process of interacting within a lecture easier by offering the facility to store a user's regularly used Textwall ${ }^{\mathrm{TM}}$ codes so that it can then automatically be added at the start of each message, Fig. 2 a, or multiple choice response Fig. 2 b.

\section{Participants}

The participants in this study were 347 students who undertook a series of four modules during the 2014/15 academic year, within the Faculty of Science at Liverpool John Moores University. Modules are classified according to the UK Framework for Higher Education Qualifications (FHEQ) where levels 4, 5 and 6 represent each of the annual sessions during a standard three-year UK degree programme. Participants were comprised of 172 Level 3 (pre-degree) students on the Foundation Natural Science programme and 175 (136 Level 4, 29 Level 5) degree students undertaking pharmaceutical science modules. Level 3 students were invited to use the application up to twice a week during separate classes on introductory chemistry and data analysis over twelve weeks during semester one. Level 4 and 5 students were encouraged to use the application within five and seven sessions, respectively, covering mathematically-based concepts over the course of semester two. Class sizes ranged from 29 to 172 and all sessions adopted a lecture format built around

\footnotetext{
${ }^{1}$ https://play.google.com/store/apps/details?id=com.ljmu.ac.uk. mywallmate\&hl=en GB

${ }^{2}$ https://itunes.apple.com/gb/app/mywallmate/id956563449?mt=8
}

three to four multiple choice questions and opportunities for students to pose queries and share comments, all facilitated by Textwall ${ }^{\mathrm{TM}}$. The application displays the number of responses to multiple choice questions and this was found to vary considerably between sessions, combined responses representing between one-quarter and three-quarters of attendees. The number of queries and comments sent to the Textwall ${ }^{\mathrm{TM}}$ would normally amount to two or three for a small class $(<50)$ and up to twenty for large classes $(>100)$. Queries not addressed during the session could be followed up after the class through email or the University's virtual learning environment, Blackboard.

\section{Data Collection}

The study consisted of distributing an online questionnaire that collected mainly quantitative data, although anecdotal free text comments were invited at the end of the questionnaire. This method is suitable as it is a quick and easy approach that is able to collect relevant data from a cohort that spans multiple modules and it is an effective method for evaluating user interfaces and software (Caltenco et al. 2012; Fitzpatrick et al. 2011; Root and Draper 1983).

Although the questionnaire has not been validated, which is a limitation of the study; it has been constructed based upon similar questions from the Usefulness, Satisfaction, and Ease of Use (USE) questionnaire (Lund 2001). It has also been reviewed by all authors, as well as by other colleagues in the department. It consisted of fifteen statements that were used to gauge participant's opinions about using mobile technology within taught sessions. As such, the questionnaire focused on the participant's use of Textwall ${ }^{\mathrm{TM}}$ and the MyWallMate mobile application. The first four statement were used to gather demographic information, including age, gender, level of study and familiarity of using mobile applications. The next eight questions gauged participants use of Textwall ${ }^{\mathrm{TM}}$ and MyWallMate and their feelings about using these services. The next two questions focused on gathering participant's opinions on the use of mobile devices within taught sessions and their feelings towards mobile technology as a platform to communicate to lectures within taught sessions. The final question allowed participants to add free text comments about the software.

The questionnaire was conducted online via Bristol Online Surveys $(\mathrm{BOS})^{3}$ and a link to the survey was emailed to the students. A $£ 100$ prize draw was offered to encourage completion. To protect the confidentiality of the participants, the data has been collected anonymously. Furthermore, the collection of personal, identifiable or sensitive information from participants has not been undertaken.

\footnotetext{
${ }^{3}$ http://www.survey.bris.ac.uk/
} 
Fig. 2 Screenshots from the MyWallMate mobile phone application; a interface for sending comments to Textwall ${ }^{\mathrm{TM}}$, b interface for responding to multiple choice questions

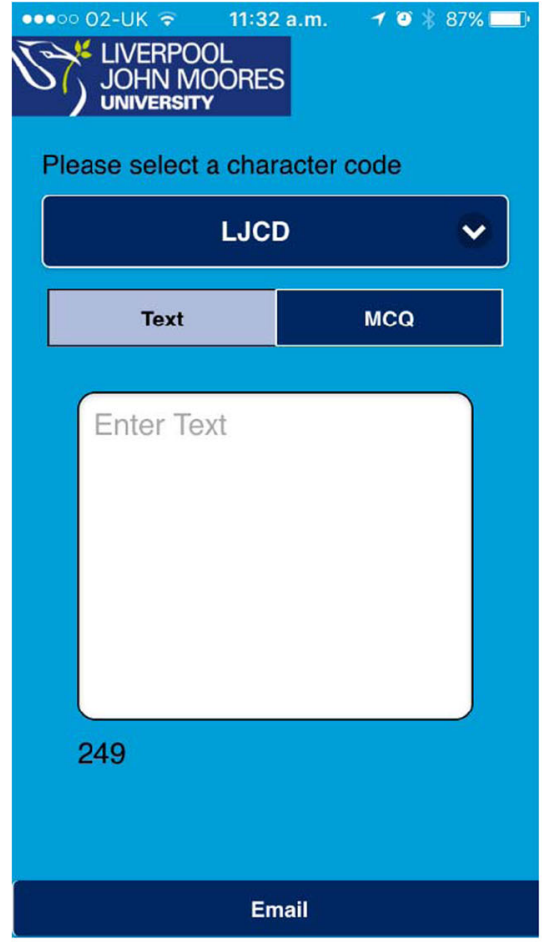

a

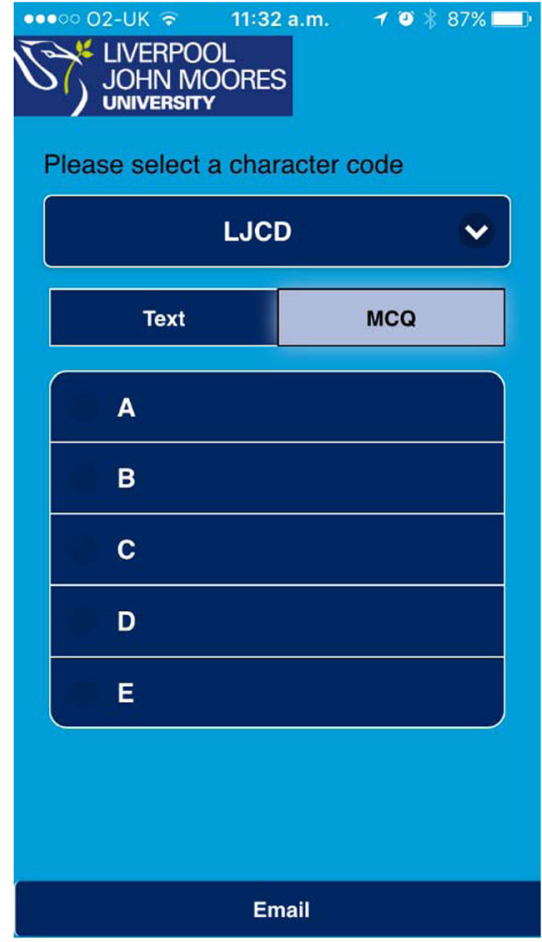

b

\section{Data Analysis}

Data analysis has been conducted on the responses that have been received from the respondents of the questionnaire. Apart from the demographic questions, the questionnaire focused on respondents measuring their agreement with each statement using a five-point Likert Scale, where $1=$ strongly disagree, 2 = disagree, $3=$ neutral, $4=$ agree, and $5=$ strongly agree. The responses have been aggregated and analysed to derive statistics, such as mean and standard deviation. They have also been divided by the sample size to calculate percentage of agreement. The open-ended question serves as anecdotal evidence to support the primary focus of analysing the quantitative data that has been received via the Likert Scale responses. As such, this data has been manually reviewed.

\section{Results}

The study consisted of fifteen questions that collected a range of information, including; demographic data, such as age, academic level and their perceived familiarity with mobile phone applications; the participant's familiarity with Textwall ${ }^{\mathrm{TM}}$; and their experience of using MyWallMate and whether they found the application to be useful within lectures. A total of 29 students completed the questionnaire. The respondents were predominantly females $(59 \%)$ compared to $41 \%$ males and ranged from ages $18-21(83 \%)$,
22-25 (7\%), 26-30 (3\%), 31-40 (3\%) and 40+ (3\%). Furthermore, $48 \%$ of respondents were Foundation level students, $41 \%$ were in their first year of undergraduate studies and $10 \%$ were in their second year of undergraduate studies. Response rates for each level were comparable and represented between eight and $10 \%$ of each surveyed year group. The vast majority of our respondents were also familiar with mobile technology, with $86 \%$ using mobile applications ("apps") on a daily basis, whilst $7 \%$ used them either often or occasionally. From these responses, we can deduce that our respondents are familiar with using mobile technology and applications.

The remaining questions were either in a Yes/No format or used a five-point Likert Scale, where Strongly Agree =5, Agree $=4$, Neutral $=3$, Disagree $=2$ and Strongly Disagree $=1$. The majority of our respondents $(97 \%)$ have used Textwall $^{\mathrm{TM}}$ to send messages or multiple-choice answers to their lecturer. Table 1 illustrates the student's responses to questions about the Textwall ${ }^{\mathrm{TM}}$ software.

Table 1 illustrates that, of the respondents who have used Textwall ${ }^{\mathrm{TM}}, 96 \%$ agreed that they felt more comfortable expressing their opinions via this outlet. The corresponding mean response of 4.43 and standard deviation (SD) of 0.57 illustrates that the majority of students agree that the technology enabled them to feel more comfortable expressing their opinions. Furthermore, $86 \%$ agreed that Textwall ${ }^{\mathrm{TM}}$ enhanced their learning of the lecture material. This is corroborated by the corresponding mean response of 4.11 and SD of 0.63 , 
Table 1 Responses to student's use of Textwall ${ }^{\mathrm{TM}}(N=28)$

\begin{tabular}{llllllll}
\hline Question & \multicolumn{2}{l}{ Response } & & & & & \\
\cline { 2 - 7 } & Strongly Agree & Agree & Neutral & Disagree & Strongly Disagree & Mean & SD \\
\hline $\begin{array}{l}\text { Using Textwall, I felt more comfortable expressing my } \\
\begin{array}{l}\text { opinions about the material of the lecture. } \\
\text { Using Textwall enhanced my learning of the lecture material. }\end{array}\end{array}$ & $46 \%$ & $50 \%$ & $4 \%$ & $0 \%$ & $0 \%$ & 0.57 \\
\hline
\end{tabular}

which illustrates that the majority of students are in agreement that Textwall ${ }^{\mathrm{TM}}$ enhanced their learning.

Table 2 illustrates the responses from respondents who have used the MyWallMate mobile application. Of these respondents, $79 \%$ agreed that the MyWallmate application was easy to use and that the layout was simple to understand $(91 \%)$. The corresponding mean responses of 4.21 and 4.50 , with SD's of 0.80 and 0.67 , respectively, illustrates that the majority of students agree that the mobile application was straightforward to use. Furthermore, $84 \%$ of students found that the application was an enjoyable addition to the lecture. This corresponds to a mean response of 4.50 and SD of 0.80 , which illustrates that the majority of students enjoyed using the mobile technology within their lectures.

The next set of questions gathered a more general opinion of the use of mobile technology within taught sessions. Figure 3 illustrates responses to the statements a) "In future taught sessions I would like to use my mobile device more regularly as part of the session" and b) "Using mobile technologies is a good way for me to become more involved in lectures" $(N=29)$. From the responses to question a), $90 \%$ of students agree that the use of mobile devices in taught sessions is attractive to students. This corresponds to a mean response of 4.07 and SD of 0.84 , which illustrates that the majority of students would like to see this technology used more regularly within their taught sessions. Responses to question b), illustrates that students were unequivocal that the use of mobile technology presented a good way for them to become more involved in lectures, with $94 \%$ of respondents endorsing this view. This corresponds to a mean response of 4.21 and SD of 0.56 , which illustrates that the majority of students agree that mobile technology, is a good way to interact within lectures.

Additionally, students have also been allowed to provide free text comments about their opinions of the Textwall ${ }^{\mathrm{TM}}$ and MyWallMate software. Below is a sample of comments that have been received:

I would like there to be questions at the end of the lectures so students can post answers via textwall as it enhances learning and makes students more interested and entertained in lecture.

As someone who is shy and wouldn't usually vocally participate during lectures, I found using Textwall was an easy way to answer questions during lectures and therefore furthering my knowledge in the subject anonymously

For those of us who are maybe too shy to ask questions in front of everyone or fear the question being too 'stupid'- it is great.

These responses can be interpreted in a positive manner in that students felt that the technology was a useful tool that enabled shy students in particular, to get involved in lectures and ask questions. Therefore, the use of mobile technology has been particularly beneficial and useful to their lectures as it enhanced their learning, as without this technology, these students might not have asked questions. These responses reinforce the idea that introducing technology into lectures present the potential for positive student experiences. In particular, the use of technology is appealing for facilitating the anonymous voicing of questions for students who may lack the confidence to speak within a lecture.

\section{Discussion}

This paper demonstrates results that have been obtained from our study into the use of mobile technology within higher education. The findings of our study are in line and support previous studies in this area. For instance, our results illustrate that almost all respondents $(96 \%)$ agreed that they felt more comfortable expressing their opinions via Textwall ${ }^{\mathrm{TM}}$, Table 1. This supports the findings of Tarrant (2012) that mobile technology offers an attractive means of eliciting student comments during lecture sessions. Furthermore, a large majority of respondents $(86 \%)$ agreed that Textwall ${ }^{\mathrm{TM}}$ enhanced their learning of the lecture material, Tables 1, and $84 \%$ agreed that using the MyWallmate mobile application within their lectures was enjoyable, Table 2. These results reinforce Mouza and Barrett-Greenly's (2015, p. 13) call for lecturers to embrace mobile technologies and that there is a "need for continuous PD [professional development] and support that helps teachers realize and capitalize on the affordances of mobile devices including ways in which they evaluate student learning". Nearly all survey respondents (90\%) felt that using a mobile devices within taught sessions is an attractive option, 
Table 2 Student's responses to the MyWallMate mobile application

\begin{tabular}{|c|c|c|c|c|c|c|c|}
\hline \multirow[t]{2}{*}{ Question } & \multicolumn{7}{|l|}{ Response } \\
\hline & Strongly Agree & Agree & Neutral & Disagree & Strongly Disagree & Mean & SD \\
\hline The MyWallmate application was easy to use $(N=14)$ & $43 \%$ & $36 \%$ & $21 \%$ & $0 \%$ & $0 \%$ & 4.21 & 0.80 \\
\hline I found the layout of the application easy to understand $(N=12)$ & $58 \%$ & $33 \%$ & $8 \%$ & $0 \%$ & $0 \%$ & 4.50 & 0.67 \\
\hline $\begin{array}{l}\text { I found that MyWallApp application provided an enjoyable } \\
\text { addition to the lecture }(N=12)\end{array}$ & $67 \%$ & $17 \%$ & $17 \%$ & $0 \%$ & $0 \%$ & 4.50 & 0.80 \\
\hline
\end{tabular}

and that the use of mobile technology presented a good way for them to become more involved in lectures, Fig. 3. These findings are in line with those of Cheon et al. (2012), who found that the attitude towards adopting mobile learning was mostly positive, and Woodcock et al. (2012) who report that students are open to the potential of using their smartphones and their applications to support their learning.

The survey outcomes confirm our original hypothesis that introducing mobile technology into lectures is a suitable method for engaging students and that students became more involved in sessions as a consequence of their use. Students thought that the technology enhanced their learning of the lecture material and that it was an effective outlet to express their opinions.

This study finds mobile technology to be a learning facilitator that students favour. Consequently, this study has implications for practice within the classroom as it is suggested that integrating mobile technologies within lectures should be further developed. Notably, these technologies enable lecturers to interact with the entire class and provides an outlet for reserved students to communicate comfortably. This is especially important for large group teaching where interaction with the entire class is difficult and where students may not feel comfortable conversing in front of the entire group. This type of teaching predominates at lower levels and it is imperative to adopt a "sound pedagogy" to ensure that students' first-year experiences are positive (Blagburn and Cloutterbuck 2011).
This can be achieved by shaping the teaching programme in "new and perhaps innovative ways [that] can assist students with social and academic engagement" (Blagburn and Cloutterbuck 2011, p. 20). Using technology as a means for students to engage in their lectures allows them to develop a sense of community within their class, with the lecturer, and with their wider peer group. It is important to instil this feeling early on, as the success of the transition of first/foundation students into university has been identified as a major element in promoting retention (Blagburn and Cloutterbuck 2011).

As the profile of the modern student changes, it is important to understand the role that technology now plays in our students lives and to capitalise on new technology in order to engage with students on a platform that they regularly utilise. Instead of shunning these devices, the higher education teaching community needs to embrace the moving tides of technology to capitalise on this growing phenomenon. Although this study was undertaken in a specific setting, the results are in line with previous studies suggesting the findings can be generalised to a wider audience of educational mobile apps (Cheon et al. 2012; Gikas and Grant 2013; West 2013).

\section{Conclusions and Future Work}

As the mobile application market increases this affords us with new and innovative ways to integrate this type of technology
Fig. 3 Responses to the statements, a "In future taught sessions I would like to use my mobile device more regularly as part of the session" and $\mathbf{b}$ "Using mobile technologies is a good way for me to become more involved in lectures" $(N=29)$

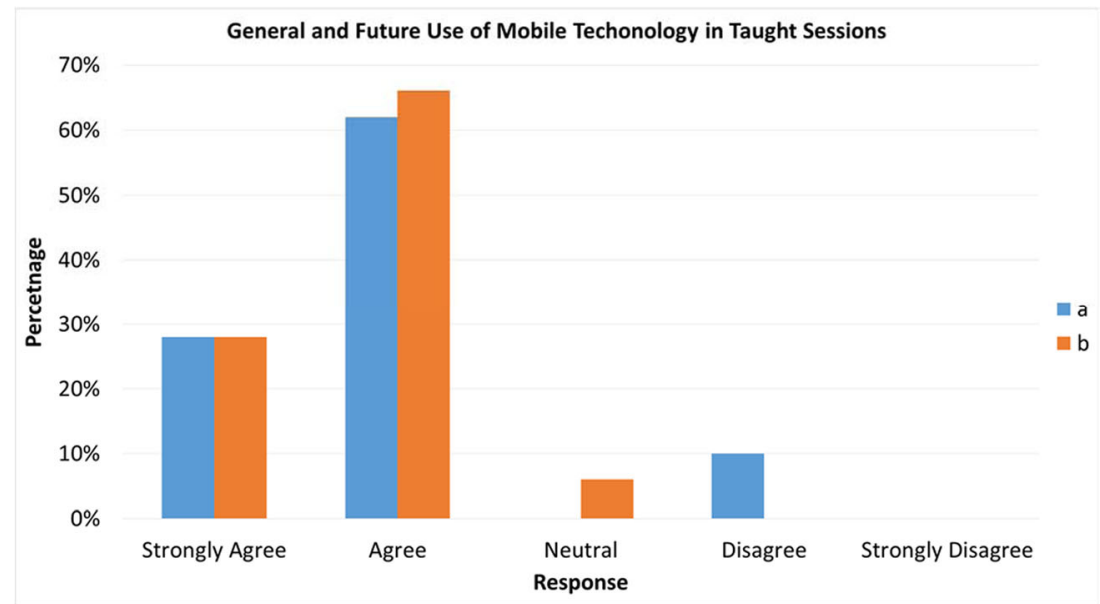


into higher education. This study has revealed the positivity that students feel about integrating such technology into their lectures. It is clear from the literature that innovative solutions are required to assist students with academic engagement. As demonstrated by this study, the use of mobile applications is seen as a positive step to achieve this. The results suggest that students appreciate this type of interaction and see it as a positive addition to their learning. We can draw from the students' comments that they thought it was an effective method to use that allowed them to ask questions, especially for those that are normally reserved and unwilling to speak in front of their peers. Future work could examine the impact that the use of mobile technologies has on attendance and attainment.

Compliance with Ethical Standards This study has received ethical approval from the Research Ethics Committee (REC) at Liverpool John Moores University (Ref No.: 15/CMP/003). Participants have been recruited via email and were provided with an information sheet that detailed the purpose of the research. At the beginning of the questionnaire, there was a statement advising participants that by completing the questionnaire they were providing their informed consent to participate.

Open Access This article is distributed under the terms of the Creative Commons Attribution 4.0 International License (http:// creativecommons.org/licenses/by/4.0/), which permits unrestricted use, distribution, and reproduction in any medium, provided you give appropriate credit to the original author(s) and the source, provide a link to the Creative Commons license, and indicate if changes were made.

\section{References}

Ally, M., \& Prieto-Blázquez, J. (2014). What is the future of mobile learning in education? Mobile Learning Applications in Higher Education [Special Section]. Revista de Universidad Y Sociedad Del Conoci- Miento (RUSC), 11(1), 142-151. doi:10.7238/rusc. v11i1.2033.

Astin, A. W. (1984). Student involvement: A developmental theory for higher education. Journal of College Student Personnel, 25(4), 297308 Retrieved from http://kvccdocs.com/KVCC/2013-Spring/ FY125-OLA/content/L-17/Student Involvement Article.pdf.

Bachmann, A. M. R., Menestrina, R. V., \& Domingues, M. J. (2015). The M-learning use in higher education: A study in Santa Catarina universities. In 2015 Ninth International Conference on Complex, Intelligent, and Software Intensive Systems (CISIS'15) (pp. 427429). IEEE. doi: 10.1109/CISIS.2015.61

Blagburn, P., \& Cloutterbuck, S. (2011). A multi-disciplinary approach to supporting student transition into higher education: A pilot study. Investigations in University Teaching and Learning, 7, 16-23.

Bowen, K., \& Pistilli, M. D. (2012). Student preferences for mobile app usage. EDUCAUSE: Center For Applied Research.

Burd, E., \& Hodgson, B. (2006). Attendance and attainment: A five year study. Innovation in Teaching and Learning in Information and Computer Sciences, 5(2). doi:10.11120/ital.2006.05020004.

Caltenco, H. A., Breidegard, B., Jönsson, B., \& Andreasen Struijk, L. N. S. (2012). Understanding Computer users with tetraplegia: Survey of assistive technology users. International Journal Of HumanComputer Interaction, 28(4), 258-268. doi:10.1080/10447318. 2011.586305.

Cheon, J., Lee, S., Crooks, S. M., \& Song, J. (2012). An investigation of mobile learning readiness in higher education based on the theory of planned behavior. Computers and Education, 59(3), 1054-1064. doi:10.1016/j.compedu.2012.04.015.

Coates, H. (2005). The value of student engagement for higher education quality assurance. Quality in Higher Education, 11(1), 25-36. doi: 10.1080/13538320500074915.

Colby, J. (2005). Attendance and attainment - a comparative study. Innovation in Teaching and Learning in Information and Computer Sciences, 4(2), 11. doi:10.11120/ital.2005.04020002.

Crow, R., Santos, I. M., LeBaron, J., McFadden, A. T., \& Osborne, C. F. (2010). Switching gears: Moving from e-learning to m-learning. MERLOT Journal of Online Learning and Teaching, 6(1), 268-278.

Dahlstrom, E., \& Bichsel, J. (2014). ECAR Study of Undergraduate Students and Information Technology, 2014. Retrieved from https://net.educause.edu/ir/library/pdf/ss14/ERS1406.pdf.

Dolnicar, S., Kaiser, S., Matus, K., \& Vialle, W. (2009). Can Australian universities take measures to increase the lecture attendance of marketing students? Journal of Marketing Education, 31(3), 203-211. doi: $10.1177 / 0273475309345202$.

Field, S. (2012). Understanding attendance and non-attendance motivation amongst first year undergraduate students. In SOLSTICE \& CLTR Conference 2012 (pp. 1-12).

Fitzpatrick, J., Cronin, K., \& Byrne, E. (2011). Is attending lectures still relevant in engineering education? European Journal of Engineering Education, 36(3), 301-312. doi:10.1080/03043797. 2011.585226.

Fredricks, J. A., Blumenfeld, P. C., \& Paris, A. H. (2004). School engagement: Potential of the concept, state of the evidence. Review of Educational Research, 74(1), 59-109. doi:10.3102/ 00346543074001059.

Friedman, P., Rodriguez, F., \& McComb, J. (2014). Why students do and do not attend classes. College Teaching, 49(4), 124-133. doi:10. 1080/87567555.2001.10844593.

Gikas, J., \& Grant, M. M. (2013). Mobile computing devices in higher education: Student perspectives on learning with cellphones, smartphones \& social media. The Internet and Higher Education, 19, 18-26. doi:10.1016/j.iheduc.2013.06.002.

Hake, R. R. (1998). Interactive-engagement versus traditional methods: A six-thousand-student survey of mechanics test data for introductory physics courses. American Journal of Physics, 66(1), 64-74. doi:10. $1119 / 1.18809$.

Jacob, S.M., \& Issac, B. (2008). The mobile devices and its mobile learning usage analysis. In Proceedings of the International MultiConference of Engineers and Computer Scientists (Vol. I, pp. 19-21). Hong Kong. Retrieved from http://arxiv.org/ftp/arxiv/ papers/1410/1410.4375.pdf.

Krause, K. (2005). Understanding and promoting student engagement in university learning communities. In Paper presented as a keynote address "Engaged, inert or otherwise occupied?: Deconstructing the 21st century undergraduate student" at the James Cook University Symposium 2005, Sharing Scholarship in Learning and Teaching: Engaging Students (pp. 21-22). Townsville/Cairns, Queensland, Australia: Centre for the study of higher education. Retrieved from http://learningspaces.edu.au/herg/assets/resources/ StudengKrause.pdf.

Krause, K., \& Armitage, L. (2014). Australian student engagement, belonging, retention and success : A synthesis of the literature. The Higher Education Academy.

Kuh, G. D. (2003). What We're learning about student engagement from NSSE: Benchmarks for effective educational practices. Change: The Magazine of Higher Learning, 35(2), 24-32. doi:10.1080/ 00091380309604090.

Kuh, G. D., Cruce, T. M., Shoup, R., Kinzie, J., \& Gonyea, R. M. (2008). Unmasking the effects of student engagement on first-year college grades and persistence. The Journal of Higher Education, 79(5), 540-563 Retrieved from http://www.jstor.org/stable/25144692? seq=1\#page_scan_tab_contents. 
Landin, M., \& Pérez, J. (2015). Class attendance and academic achievement of pharmacy students in a European university. Currents in Pharmacy Teaching and Learning, 7(1), 78-83. doi:10.1016/j.cptl. 2014.09.013.

Lewis, T. L., Burnett, B., Tunstall, R. G., \& Abrahams, P. H. (2014). Complementing anatomy education using three-dimensional anatomy mobile software applications on tablet computers. Clinical Anatomy - Special Issue: Special Issue on the Clinical Anatomy of the Young and Aging, 27(3), 313-320. doi:10.1002/ca.22256.

Lopez, J. P., Cerezo, A., Menendez, J. M., \& Ballesteros, J. P. (2015). Usage of mobile devices as collaborative tools for education and preparation of official exams. In 2015 I.E. International Symposium on Consumer Electronics (ISCE'15) (pp. 1-2). IEEE. Doi:10.1109/ISCE.2015.7177809

Lund, A. M. (2001). Measuring usability with the USE questionnaire. STC Usability SIG Newsletter, 8(2), 3-6 Retrieved from http:// garyperlman.com/quest/quest.cgi?form=USE.

Mackley, D. (2014). A-Z Tools \& Technologies: Textwall. Retrieved November 18, 2015, from https://blog.yorksj.ac.uk/moodle/2014/ 03/27/textwall/.

Mouza, C., \& Barrett-Greenly, T. (2015). Bridging the app gap: An examination of a professional development initiative on mobile learning in urban schools. Computers \& Education, 88, 1-14. doi:10. 1016/j.compedu.2015.04.009.

Ntinda, M., Thinyane, H., \& Sieborger, I. (2014). M-learning system enhancing mathematical concepts (m-LSEMC): A case study of University of Namibia and Rhodes. In 2014 IST-Africa Conference Proceedings (pp. 1-13). Le Meridien Ile Maurice: IEEE. doi:10. 1109/ISTAFRICA.2014.6880659.

O’Malley, C., Vavoula, G., Glew, J., Taylor, J., Sharples, M., Lefrere, P., Waycott, J. (2005). Guidelines for learning/teaching/tutoring in a mobile environment. Public deliverable from the MOBILearn project. Retrieved from https://hal.archives-ouvertes.fr/hal-00696244/ document.

Page, T. (2014). Application-based mobile devices in design education. International Journal of Mobile Learning and Organisation, 8(2), 96. doi:10.1504/IJMLO.2014.062347.

Pegrum, M. (2015). Mobile learning: What is it and what are its possibilities? In M. Henderson \& G. Romeo (Eds.), Teaching and Digital
Technologies: Big Issues and Critical Questions (p. 143). Cambridge.

Prince, M. (2004). Does active learning work? A Review of the research. Journal of Engineering Education, 93(3), 223-231 Retrieved from http://onlinelibrary.wiley.com/doi/10.1002/j.2168-9830.2004. tb00809.x/abstract.

Root, R. W., \& Draper, S. (1983). Questionnaires as a software evaluation tool. In Proceedings of the SIGCHI Conference on human factors in computing systems (pp. 83-87). New York: ACM Press. doi:10. $1145 / 800045.801586$.

Rothwell, P. (2016). Mobile moments: How modern students make learning their own. In Innovate \& Educate's Teaching and Learning Conference by Blackboard (BbTLC16). Groningen, The Netherlands, 6th - 8th April.

Steinert, Y., \& Snell, L. S. (1999). Interactive lecturing: Strategies for increasing participation in large group presentations. Medical Teacher, 21(1), 37-42. doi:10.1080/01421599980011.

Tarrant, A. (2012). Using a text wall in HE Teaching. Retrieved November 18, 2015, from https://dratarrant.wordpress.com/2012/ 01/30/using-a-text-wall-in-he-teaching/.

Trowler, V. (2010). Student Engagement Literature Review. The Higher Education Academy, (November), 3. Retrieved from http://wwwnew2.heacademy.ac.uk/assets/documents/studentengagement/ StudentEngagementLiteratureReview.pdf.

van Schalkwyk, S., Menkveld, H., \& Ruiters, J. (2010). What's the story with class attendance? First-year students: Statistics and perspectives. South African Journal of Higher Education, 24(4), 630-645 Retrieved from http://eproxy.ucd.ie/login?url=http:// s e a r ch.proquest.com/professional/docview/ 898326144?accountid=14507\%5Cnhttp://ibraryjournals.ucd.ie/ sfxlcl3?url_ver=Z39.88-2004\&rft_val_fmt=info:ofi/fmt:kev:mtx: journal\&genre=article\&sid=ProQ:ProQ:ericshell\&atitle $=$ What.

West, D. M. (2013). Mobile learning: Transforming education, engaging students, and improving outcomes. Brookings Policy Report, 1-7.

Woodcock, B., Middleton, A., \& Nortcliffe, A. (2012). Considering the smartphone learner: An investigation into student interest in the use of personal technology to enhance their learning. Student Engagement and Experience Journal, 1(1), 1-15. doi:10.7190/ seej.v1i1.38. 